CASO CLÍ NI CO

\title{
Monocephalus dipygus EN CACHARROS: REPORTE DE DOS CASOS
}

\section{Monocephalus dipygus I N PUPPIES: REPORT OF TWO CASES}

\author{
Teresa Oviedo S, ${ }^{* 1}$ M.Sc, Marco González T, ${ }^{1}$ M.Sc, Misael Oviedo P, ${ }^{2}$ Esp. \\ ${ }^{1}$ Universidad de Córdoba, Facultad de Medicina Veterinaria y Zootecnia, Departamento \\ de Ciencias Pecuarias, Montería - Colombia. ${ }^{2}$ Práctica privada. ${ }^{*}$ Correspondencia: \\ tere_oviedo@yahoo.com
}

Recibido: Febrero 12 de 2008; Aceptado: Diciembre 19 de 2008

\section{RESUMEN}

Se describen dos casos de duplicación posterior congénita en cachorros. Esta malformación también conocida como Monocephalus dipygus, hace referencia a individuos dobles, caracterizados por tener cabeza y tórax fusionados en uno solo, duplicidad simétrica de pelvis y miembros posteriores. El primer caso, presentó cuatro miembros anteriores, cuatro miembros posteriores y palatosquisis. El segundo caso, presentó dos miembros anteriores y cuatro miembros posteriores. En general, ambos casos pueden ser relacionados como gemelos fusionados simétricos.

Palabras clave: Alteraciones congénitas, malformación fetal, duplicación.

\begin{abstract}
It is described two cases of congenital posterior duplication in puppies. This malformation also known as Monocephalus dipygus refers to individuals doubles, characterized by having the head and thorax fused into a single and symmetrical duplication of pelvis and hind limbs. The first case, showed four former members, four posterior members and palatosquisis. The second case, showed only two former members and four posterior members. In general, both cases can be related as twins symmetric fused.
\end{abstract}

Key words: Congenital abnormalities, fetal malformation, duplication 


\section{NTRODUCCIÓN}

Las anomalías congénitas son defectos que están presentes en el momento del nacimiento y se deben a errores durante el desarrollo embrionario (1). Un ejemplo de estas alteraciones corresponde a los gemelos unidos generalmente conocidos como siameses, los cuales son producto de la división incompleta de un óvulo fecundado (gemelos monocigóticos). Lo anterior, tiene como consecuencia el desarrollo de individuos con duplicaciones completas o incompletas que pueden ser simétricas 0 asimétricas.

Según Sadler (2), la clasificación de los gemelos unidos se fundamenta en la naturaleza y el grado de unión de los mismos, el dipygus por ejemplo, es el nombre dado a individuos dobles caracterizados por tener su cabeza y tórax completamente fusionados, presentan además pelvis y extremidades posteriores duplicadas y simétricas. También pueden presentar 2 ó 4 miembros anteriores.

Los trastornos teratogénicos de gemelos unidos son más comunes en el ganado bovino y se calcula que se presentan una vez cada 100.000 nacimientos. No obstante, rara vez se describe su presentación en ovinos, porcinos, perros, gatos y caballos (3-8). No siempre es posible determinar las causas específicas de estas patologías, pero se ha asociado a factores genéticos como las anomalías cromosómicas, agentes tóxicos como medicamentos, plantas y agentes infecciosos como los virus entre otros (9).

En el presente trabajo se describen dos casos de Monocephalus dipygus en cachorros recién nacidos provenientes de diferentes madres.

Caso 1. Cachorro de sexo masculino, proveniente de madre sin raza definida, que presentó fusión de cabeza y tronco hasta las costillas, observándose estas estructuras de mayor amplitud que en un cachorro normal. A pesar de haber presentado fusión de la cabeza, existió una clara fisura en la línea media de la misma, la cual fue más evidente en la región del hocico (Figura 1).
Al inspeccionar la cavidad bucal se determinó la presencia de paladar hendido o palatosquisis. Por otra parte, el cachorro presentó 4 miembros anteriores, de los cuales dos presentaron una orientación espacial normal con relación a la cabeza y los otros dos estaban ubicados dorsalmente (Figura $2)$. Por debajo de las costillas presentó independencia total y simetría de las estructuras anatómicas externas, como pelvis, miembros, cola y cordón umbilical (Figura 3).

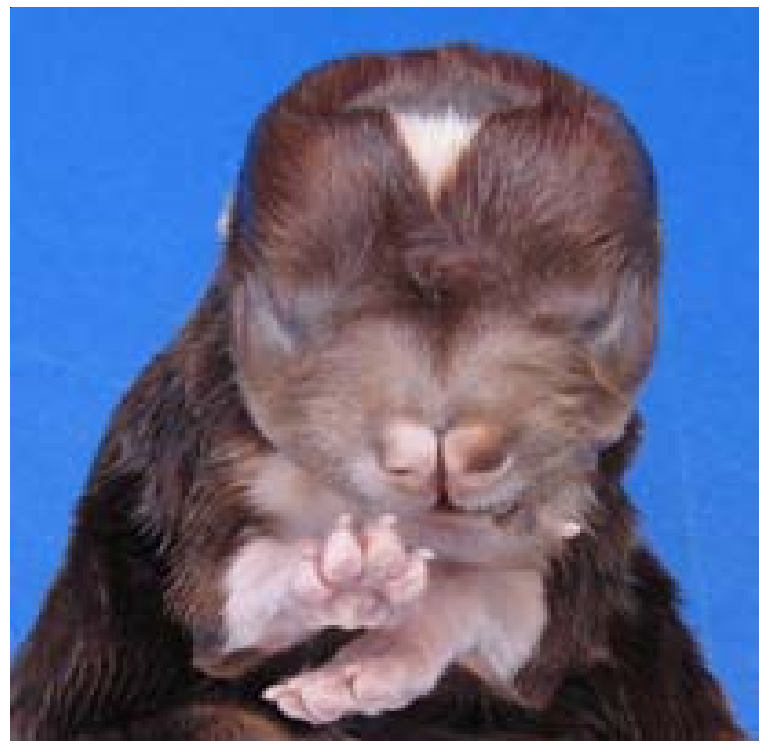

Figura 1. Vista craneal en donde se observa la mayor amplitud del rostro y la fisura central que lo divide.

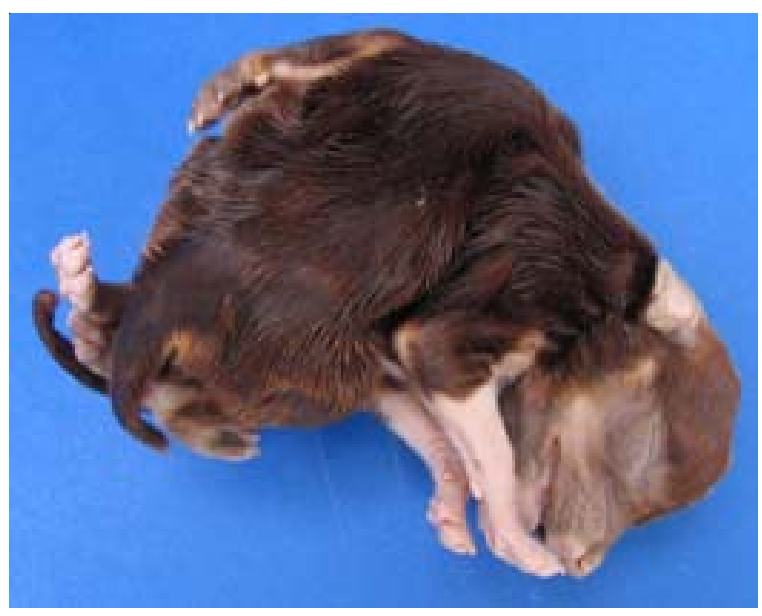

Figura 2. Vista lateral en donde se observa la presencia de cuatro miembros anteriores y su ubicación espacial con respecto al rostro. 


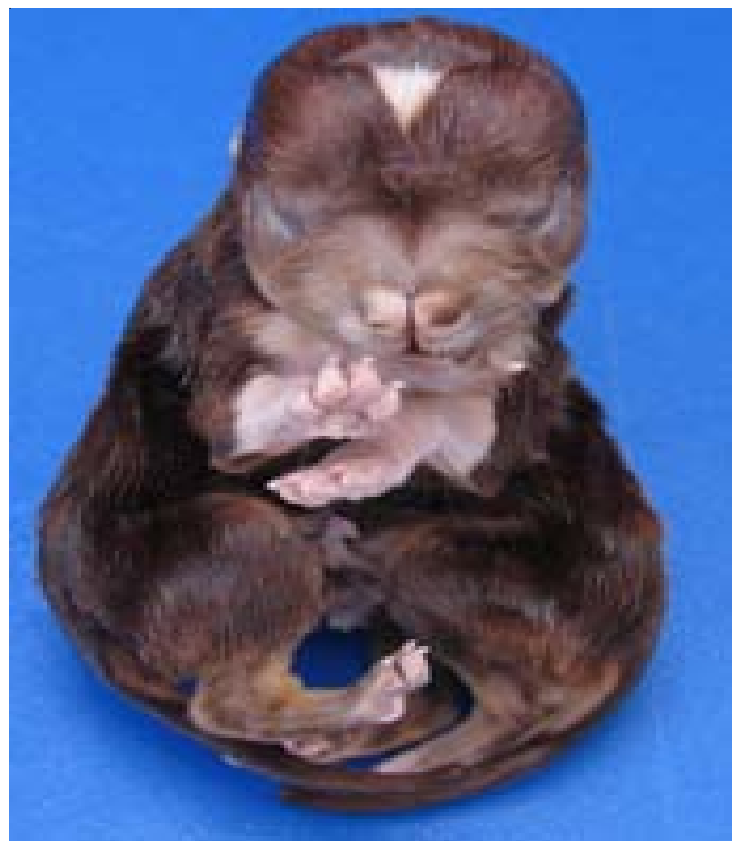

Figura 3. Vista ventral en donde se observa la duplicidad de miembros posteriores.

Caso 2. Cachorro de sexo femenino, proveniente de madre sin raza definida, que presentó fusión de cabeza y tórax con duplicación posterior simétrica. Aunque el cráneo del animal mostró cierto ensanchamiento, no se observó fisura en la línea media del mismo, lo que a la inspección ligera se vería muy semejante al cráneo y rostro de un cachorro anatómicamente normal (Figura 4). Al inspeccionar la cavidad bucal no se observó paladar hendido. Presentó solo dos miembros anteriores cuya

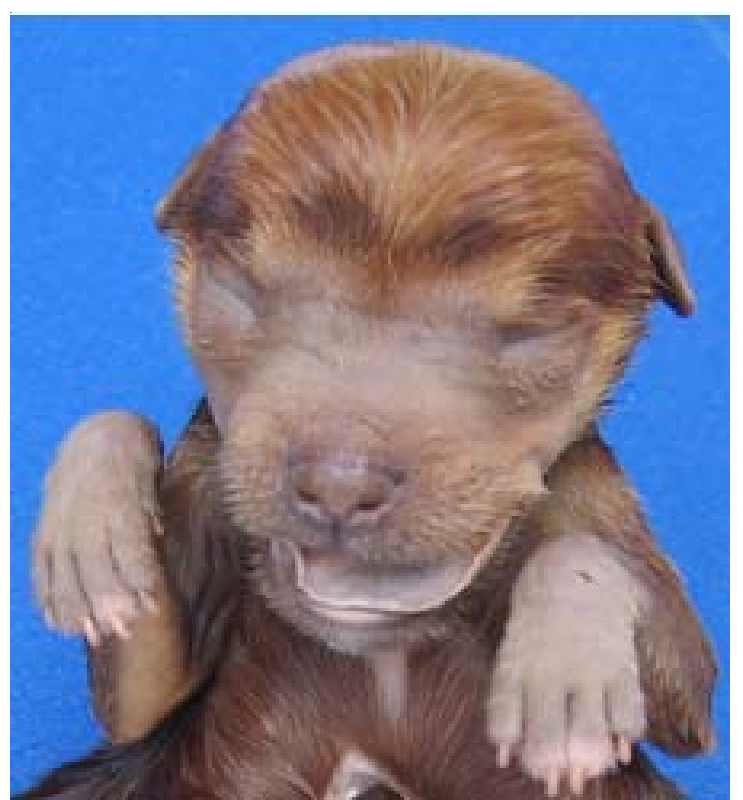

Figura 4. Vista craneal mostrando semejanza con un cachorro normal y ubicación normal de los miembros anteriores con relación a la cabeza.

orientación espacial fue normal con relación a la cabeza (Figura 4). Por detrás de las costillas exhibió duplicidad total y simétrica de la pelvis, miembros, cola y cordón umbilical (Figura 5).

En ambos casos se desconoce el manejo y las condiciones sanitarias de las madres. No hubo antecedentes de uso de sustancias relacionadas con el origen de anormalidades congénitas.

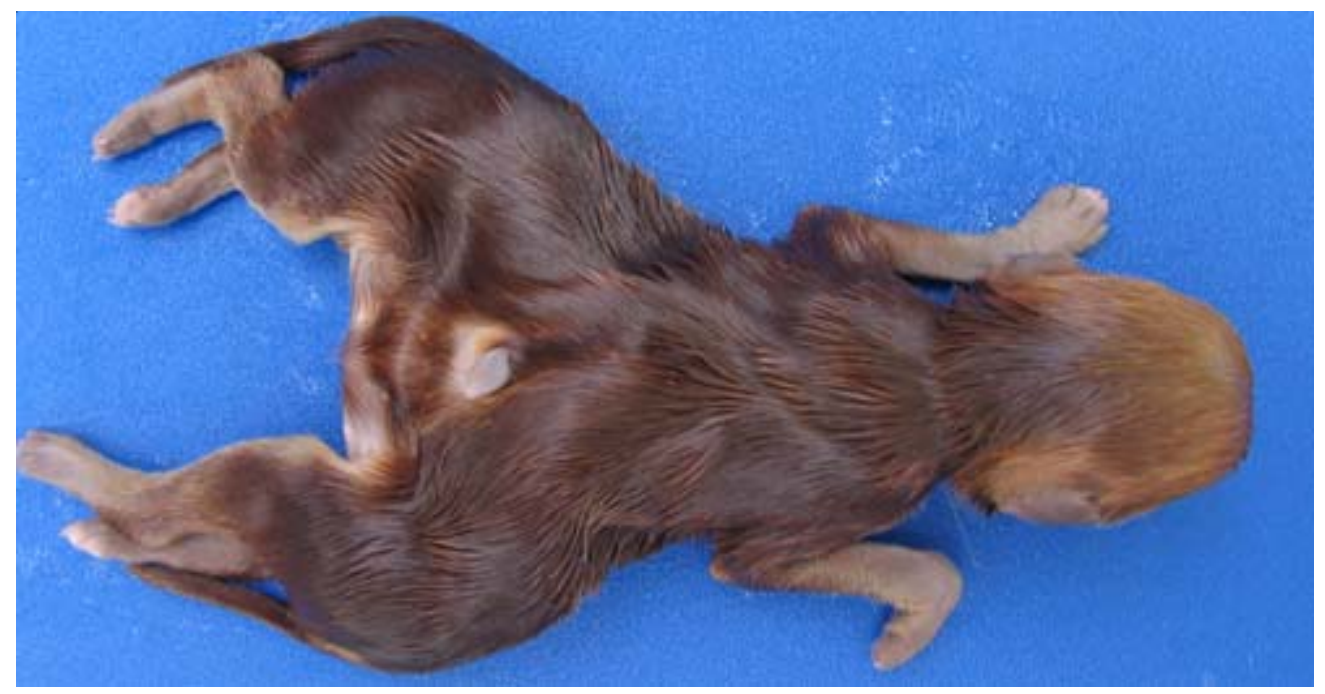

Figura 5. Vista dorsal donde se aprecia la presencia de dos miembros anteriores y duplicidad de miembros posteriores. 


\section{DISCUSIÓN}

La separación parcial de blastómeros y blastocitos, o duplicaciones durante la gastrulación es un hecho que puede originar duplicidad de individuos, los cuales pueden ser clasificados como libres o unidos, y simétricos o asimétricos (1).

Una de las formas en que se pueden observar estas anomalías consiste en la presencia de una cabeza única, (Monocephalus) con duplicación en la región caudal (dipygus). Esta alteración está generalmente acompañada de una duplicación parcial o completa de la pelvis con cuatro extremidades (Tetrapus), lo cual fue observado en los casos reportados en el presente manuscrito. Con relación a los miembros anteriores, existen reportes de animales Monocephalus con cuatro miembros (tetrabrachius) (10), y dos miembros (dibrachius) (11).
En términos generales, los dos casos descritos corresponden a gemelos simétricos unidos (Monocephalus dipygus), clasificando el primero de ellos como Monocephalus thoracopagus tetrabrachius tetrapus, por presentar fusión de cabeza y tórax, así como cuatro miembros anteriores y cuatro posteriores. El segundo caso, por el hecho de presentar sólo dos miembros anteriores es clasificado como Monocephalus thoracopagus dibrachius tetrapus. EI Monocephalus dipygus es una alteración congénita que ha sido descrita en perros con características similares al primer caso presentado (10).

Por lo general, se desconocen las causas específicas de estas alteraciones, no obstante se cree que se deben a factores genéticos como las anomalías cromosómicas y a factores ambientales como medicamentos, plantas, virus, entre otros $(9,11)$.

\section{REFERENCI AS}

1. Noden DM, De Lahunta A. The embryology of Domestic Animals. Development Mechanisms and Malformations. Baltimore. USA: Williams and Wilkins; 1985.

2. Sadler TW. Langman's Medical Embryology. $8^{\text {th }}$ ed. Lippincott: Williams and Wilkins; 2000.

3. Roberts SJ. Gestation period: embryology, fetal membranes and placenta. In: Veterinary Obstetrics and Genital Diseases (Theriogenology) $3^{\text {th }}$ ed. (SJ Roberts, ed) Ann Arbor, MI : Edwards Brothers; 1986.

4. Götz HJ. A case of diprosopus in a foal. Tierarztl Prax 1991; 19(1): 82-83.

5. Vale Echeto O, Alvarado Morillo M, Vale Oviedo O, Árraga de Alvarado C, Camacho Bracho J, Fernández Orozco E. Duplicidad parcial cefálicafacial (diprosopia) en bovinos: estudio clínico patológico de un caso. RC. 2004; 14(4): 338-343.

6. Aharon DC, Wouda W, Van Weelden EA. Case of diprosopus in the cat. Tijdschr Diergeneeskd 1986; 111(12):588-91.
7. Bähr C, Beineke A, Drögemüller C, Distl O. Diprosopus in calves of different breeds. Dtsch Tierarztl Wochenschr 2004; 111(4): 154-8.

8. Shojaei B, Derakhshanfar A, Oloumi MM, Hashemnia S. Diprosopus, spina bifida and kyphoscoliosis in a lamb. Vet Arhiv 2006; (76): 461-469.

9. Hiraga T, and Dennis SM. Congenital duplication. Vet. Clin. North Am. Food Anim Pract 1993; (9) : 145-58.

10. Nottidge $\mathrm{HO}$, Omobowale TO, Olopade J O, Oladiran $\mathrm{OO}$ and Ajala OO. A Case of Craniothoracopagus (Monocephalus Thoracopagus Tetrabrachius) in a Dog. Anat Histol Embryol 2007; (36): 179-181.

11. Corbera JA, Arencibia A, Morales I, Gutierrez C. Congenital duplication of the caudal region (monocephalus dipygus) in a kid goat. Anat Histol Embryol 2005; (34): 61-63. 